\title{
ANÁLISE PARÂMETROS ELÉTRICOS CONSUMO, FATOR DE CARGA E DEMANDA DE EMPRESAS DE REFINO DE ÓLEO VEGETAL
}

Camila Pires Cremasco Gabriel ${ }^{1}$

Fernando Ferrari Putti ${ }^{2}$

Pedro Fernando Cataneo ${ }^{3}$

Luís Roberto Almeida Gabriel Filho ${ }^{4}$

RESUMO: Empresas muitas vezes tem seu consumo de energia elétrica descontrolados por possuírem motores elétricos muitas vezes super-dimensionados, trabalhando em vazio ou em horário de pico. Sendo este tipo de atividade responsável por grande parte do gasto energético da empresa. Existem dois fatores que avaliam o modo de utilização desta energia, denominados fator de potência (fp) e fator de carga (fc), que indicam a

\footnotetext{
${ }^{1}$ Licenciada em Matemática (FCT/UNESP), Mestre em Matemática Pura (DM/UFSCar), Doutora em Agronomia/Energia na Agricultura (FCA/UNESP) e Pós-doutora em Bioestatística (IB/UNESP), Professora Associada da FATEC - Presidente Prudente/SP. camila@fatecpp.edu.br.

${ }^{2}$ Bacharel em Administração (TUPÃ/UNESP). Mestrando em Irrigação (FCA/UNESP). puttiff@gmail.com.

3 Bacharel em Direito, Mestre e Doutor em Agronomia/Energia na Agricultura (FCA/UNESP), Professor Assistente Doutor da CET/UNESP - Tupã/SP. cataneo@tupa.unesp.br.

${ }^{4}$ Licenciado em Matemática (FCT/UNESP), Mestre em Matemática Pura (ICMC/USP), Doutor em Agronomia/Energia na Agricultura (FCA/UNESP) e Pós-doutor em Agronomia/Energia na Agricultura (FCA/UNESP), Professor Assistente Doutor da CET/UNESP - Tupã/SP. gabrielfilho@tupa.unesp.br.
} 
eficiência e racionalidade da forma de utilização da energia elétrica, respectivamente. A necessidade de uma avaliação global da utilização da energia, levando em consideração os dois fatores citados, é realizada por especialistas da área energética para a determinação da situação real da empresa. Podendo ser uma tarefa árdua muitas vezes demorada. Para isto é necessária uma análise estatística descritiva dos dados. Este trabalho tem como objetivo realizar esta analise de dados de uma empresa de refino de óleo vegetal.

Palavras-chave: Sustentabilidade. Boxplot. Estatística descritiva.

\section{INTRODUÇÃO}

A energia elétrica e o meio ambiente tem sido assunto de grande importância tanto no meio científico quanto no cotidiano das pessoas e organizações. Existem projetos e pesquisas de grande porte envolvendo otimização de energia.

Utilizar a tecnologia e seus recursos para integrar práticas de responsabilidade sócio-ambiental é o meio em que diversas organizações encontraram para efetivamente implantar uma política de um retorno e de melhorias para o meio-ambiente e econômico. Grandes empresas já desenvolvem projetos para otimizar o recurso energia utilizando a tecnologia.

Existem dois índices que avaliam a forma com a empresa está utilizando a energia elétrica: o fator de carga (fc) e o fator de potência (fp).

O fator de carga avalia se a energia está sendo utilizada de forma racional. Quanto maior o valor do fator de carga obtido, melhor terá sido a utilização das cargas elétricas ao longo do tempo. Por outro lado, um fator de carga baixo pode indicar que houve concentração de consumo de energia elétrica em um curto período de tempo, determinando alterações na demanda.

O fator de potência (fp) é outro índice que merece uma atenção especial. Alguns aparelhos elétricos, como os motores, além de consumirem energia ativa solicitam também a energia reativa necessária para criar o fluxo magnético que 0 seu funcionamento exige. Com a relação entre estes valores, determina-se o fator de potência médio indutivo num determinado período. $O$ fator de potência é um índice que mostra o 
quanto da energia elétrica está sendo transformada em outras formas de energia. Quando o fator de potência é baixo, podem surgir problemas na instalação elétrica do consumidor e na rede de distribuição da concessionária.

Porém, existe a necessidade da existência de um único índice que indique de forma global (racional e eficiente) como a energia está sendo utilizada. Tal necessidade surge, por exemplo, quando em certos meses uma determinada empresa constata um alto fp e um baixo fc, e, em outros meses, uma situação de baixo fp e alto fc. Assim, cenários deste tipo exigem um avaliação clara e objetiva da situação em que a empresa melhor se encontra. Ainda quaisquer combinações destes índices precisam ser esclarecidas para o administrador da empresa decida se houve melhora ou não da utilização de energia elétrica pela sua unidade consumidora.

O fornecimento de energia elétrica estabelece uma estrutura tarifária, ou seja, um conjunto de tarifas aplicáveis às componentes de consumo de energia elétrica e/ou demanda de potência ativas de acordo com a modalidade de fornecimento. Existem três tipos de modalidades tarifárias para as unidades consumidoras atendidas pelo sistema elétrico: a tarifa convencional e a tarifa horo-sazonal (azul e verde).

Esta estrutura é caracterizada pela aplicação de tarifas de consumo de energia elétrica e/ou demanda de potência independentemente das horas de utilização do dia e dos períodos do ano. Também é distinguida pela aplicação de tarifas diferenciadas de consumo de energia elétrica e de demanda de potência de acordo com as horas de utilização do dia e dos períodos do ano, conforme especificação.

A tarifa verde é uma modalidade estruturada para aplicação de tarifas diferenciadas de consumo de energia elétrica de acordo com as horas de utilização do dia e os períodos do ano, com único valor de tarifa de demanda de potência.

Para a análise do faturamento da empresa utilizou-se a resolução ANEEL $\mathrm{n} \cong 456$ de 30/11/2000 que estabelece, de forma atualizada e consolidada, as condições gerais de fornecimento de energia elétrica. Neste trabalho a empresa estudada possui demanda contrata regida pela tarifa verde, logo a investigação deste trabalho focou o faturamento e suas equações da tarifa que a empresa contrata.

Este trabalho tem como objetivo analisar por meio da estatística descritiva e gráficos tipo boxplot os dados coletados da consta de energia elétrica da empresa de refino óleo vegetal. 


\section{METODOLOGIA}

Para a analise dos dados coletados foram usados os gráficos tipo boxplot que são construídos com base no resumo dos cinco números, valor mínimo, primeiro quartil (Q1), mediana (segundo quartil Q2), terceiro quartil (Q3) e valor máximo.

O gráfico é construído formando uma caixa construída paralelamente ao eixo da escala dos dados (pode ser horizontal ou vertical). Essa caixa vai desde o primeiro quartil até o terceiro quartil e nela traça-se uma linha na posição da mediana. Essa caixa, que descreve os $50 \%$ centrais da distribuição, é comum a todas as variantes do boxplot. Em casos especiais será acrescentado também uma linha, paralela à linha da mediana, para indicar a média.

\section{RESULTADOS E DISCUSSÃO}

O consumo de energia elétrica numa região não é constante; sofre fortes oscilações, em função do tempo e da atividade predominante dos consumidores.

Assim foi considerado que o conhecimento das curvas de cargas de um sistema pode ser um ponto de partida para formar uma nova distribuição de carga, com características mais favoráveis.

De acordo com Gabriel (1997), o fator de carga (FC) é o índice que mostra se a energia elétrica está sendo utilizada de forma racional por um determinado consumidor.

O fator de carga (FC) é um índice obtido através da relação entre a demanda média e a demanda máxima medida, durante um período de tempo definido. A Tabela 1, apresenta os dados da empresa.

Tabela 1. Valores mensais de demanda $(\mathrm{kW})$, consumo ativo $(\mathrm{kWh})$ e fator de carga $(\mathrm{FC})$ referentes a uma empresa de refino de óleo vegetal situada em Ourinhos-SP, observados em 2012.

\begin{tabular}{cccc}
\hline Mês & kW & kWh & FC \\
\hline Jan & 522,7 & 15.239 & 0,442 \\
Fev & 666,7 & 21.132 & 0,48 \\
Mar & $2.407,7$ & 69.943 & 0,44 \\
Abr & $2.689,9$ & 151.547 & 0,854
\end{tabular}




\begin{tabular}{cccc} 
Mai & $2.577,6$ & 159.452 & 0,937 \\
Jun & $2.463,8$ & 135.261 & 0,832 \\
Jul & $2.485,4$ & 145.851 & 0,889 \\
Ago & $2.344,3$ & 143.095 & 0,925 \\
Set & $2.216,2$ & 132.601 & 0,907 \\
Out & $2.335,7$ & 108.144 & 0,702 \\
Nov & $2.364,5$ & 82.289 & 0,527 \\
Dez & $2.266,6$ & 76.209 & 0,509 \\
\hline
\end{tabular}

Sabendo que $x=F C$ e $y=\frac{k W h}{k W}$, a Figura 1 apresenta a análise descritiva do $\mathrm{KW}$ da empresa estudada.

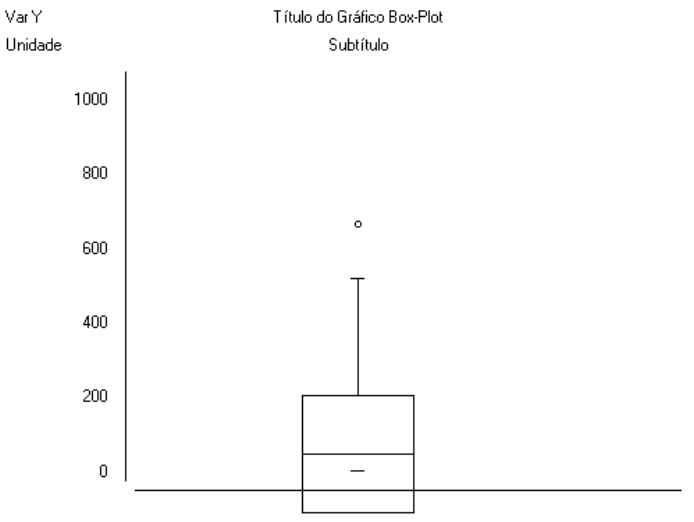

Figura 1. Gráfico Box-Plot do KW da empresa a analisada.

A análise das outras variáveis coletadas na empresa KWh e FC estão ilustradas nas Figuras 2 e 3.

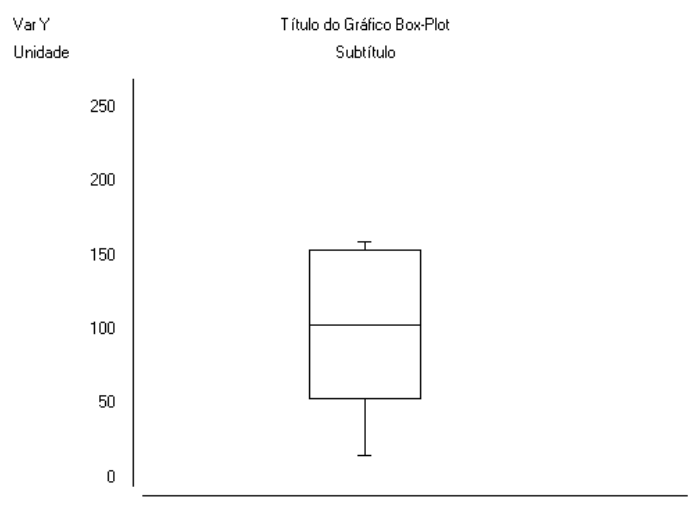


Figura 2. Gráfico Box-Plot do KWh da empresa a analisada.

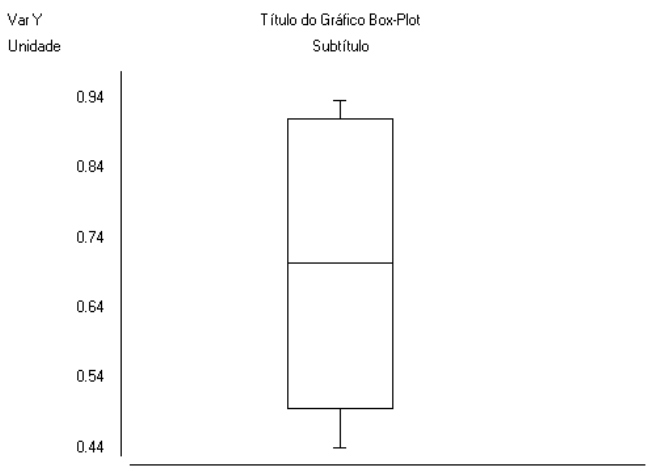

Figura 3. Gráfico Box-Plot do fc da empresa a analisada.

A tabela 2 apresenta a média e o desvio padrão dos dados coletados das contas de energia elétrica da empresa.

Tabela 2. Estatistica descritivas dos valores mensais de demanda (kW), consumo ativo (kWh) e fator de carga (FC) referentes a uma empresa de refino de óleo vegetal situada em Ourinhos-SP, observados em 2012.

\begin{tabular}{cccc}
\hline média & 2111,758 & 103396,9 & 0,703667 \\
mediana & 2354,4 & 120372,5 & 0,767 \\
mínimo & 666,7 & 21132 & 0,44 \\
máximo & 2689,9 & 159452 & 0,937 \\
qualtil & 2474,6 & 144473 & 0,898 \\
desvio padrão & 721,0262 & 50066,18 & 0,207872 \\
\hline
\end{tabular}

Este trabalho demonstra a situação da empresa em durante o ano de estudo.

REFERÊNCIAS 
CARMO, M. P. do; Differential Geometry of Curves and Surfaces. Prentice-Hall, Inc., Rio de Janeiro, Brazil, 1976.

COMPANHIA ENERGÉTICA DE SÃO PAULO. Estrutura tarifária horo-sazonal. São Paulo, 2003. 22 p.

CREMASCO, C. P. Aplicação da lógica fuzzy para avaliação do faturamento do consumo de energia elétrica e demanda de uma empresa de avicultura de postura. $97 \mathrm{f}$. Tese (Doutorado em Agronomia / Energia na Agricultura) - Universidade Estadual Paulista, Faculdade de Ciências Agrárias, Botucatu, 2008. 